\title{
Construindo a Participação Social no SUS: um constante repensar em busca de equidade $e$ transformação'
}

\section{Building Social Participation on the Brazilian Health System: a constant rethinking that seeks fairness and transformation}

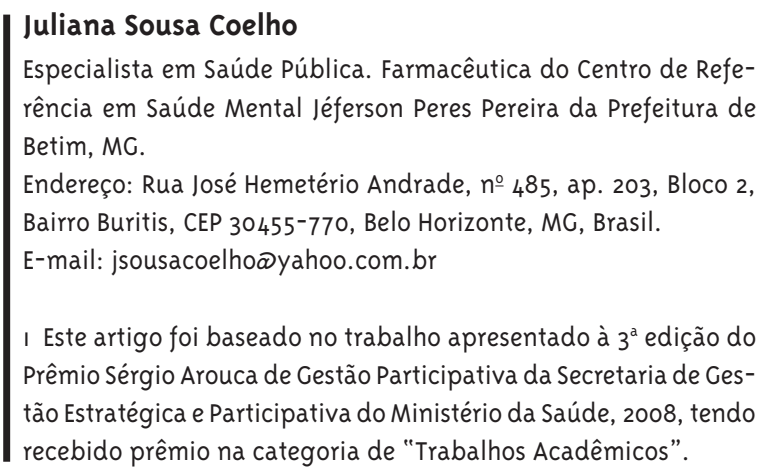

\section{Resumo}

Trata-se de um ensaio que expõe reflexões sobre a busca e o exercício da participação social no Sistema Único de Saúde (SUS), compreendendo seu conceito como as diferentes ações dos grupos sociais que influenciam a formulação, execução, fiscalização e avaliação das políticas públicas. Por isso o fato de a comunidade participar no sistema de saúde é visto como condição fundamental para o exercício pleno da saúde, capaz de promover equidade e de transformar a atenção à saúde. As ações de construir a cidadania e formar sujeitos coletivos são tomadas como fundamentos para a conquista de espaços democráticos e de direitos sociais. Mapeou-se a normatização atual referente à participação popular, considerando seus avanços, mas explicitando também suas fragilidades, principalmente no que tange aos conselhos e conferências de saúde. No ambiente dos espaços institucionais de participação, foram destacados elementos necessários para consolidar e efetivar a participação popular, como a relação entre os atores e a comunicação para a socializar as informações e conhecimentos em saúde. Busca-se também problematizar o assunto, trazendo à tona alguns dos obstáculos e críticas relativos à participação social. Pretende-se, com este ensaio, colaborar para a democratização dos diferentes espaços de escuta da sociedade civil, tornando-os locais cada vez mais apropriados para as tomadas de decisão sobre a construção de políticas e serviços de saúde, dos quais a população se apropria coletivamente, superando a simples obrigatoriedade burocrática da participação e contribuindo para a saúde e qualidade de vida.

Palavras-chave: Participação comunitária; Participação cidadã; Participação social; Participação do paciente. 


\section{Abstract}

It concerns an essay that presents reflections on the search and the practice of the social participation in the Brazilian Unified Health System (SUS), including the understanding of its concept as to how the different actions of the social groups influence the formularization, execution, fiscalization and evaluation of the public policies. Therefore the participation of the community in the health system is considered an essential condition for the full exercise of the health, capable of promoting fairness and to transforming the health attention. The building of citizenship and the formation of collective citizens are taken as beddings for the conquest of democratic spaces and social rights. The current normalization of the public participation has been mapped considering its advances, but also stating its fragilities, mainly those that concerning the participation out of health councils and conferences. In the institutional environment, some elements where pointed as necessary to consolidate and effect the communitarian participation, like the relation between the actors and the communication for the socialization of health information and knowledge. Questions of the subject are also sought by bringing to attention some of the critical obstacles in relation to the social participation. This essay is intended to collaborate in behalf of the real democratization of the different spaces where the civil society can be heard, transforming these places in more appropriate locations to make decisions concerning the construction of health policies and services. The population can benefit from these spaces collectively surpassing the simple bureaucratic obligatoriness of the participation and contributing for the health and quality of life.

Keywords: Consumer Participation; Citizen Participation; Social Participation; Patient Participation.

\section{Introdução}

O processo de construção do Sistema Único de Saúde (SUS) envolveu a participação de diversos atores sociais unidos no Movimento de Reforma Sanitária que defendia o projeto de um sistema de saúde, um plano abrangente de políticas públicas capazes de incidir sobre as condições de vida e de trabalho da população, além de prover a proteção coletiva contra agravos, garantindo a sua saúde em todos os aspectos (Valla e Stotz, 1994).

Desse projeto de sistema de saúde e de muitas lutas e debates, nasceu, na Constituição de 1988, o Sistema Único de Saúde (SUS). A sua definição legal instituiu formalmente princípios e diretrizes de universalidade, equidade, integralidade do atendimento com prioridade à prevenção, descentralização e participação da comunidade, que devem nortear as atividades em saúde.

Talvez devido à influência do imenso desejo por democracia difundido à época da construção do SUS, caracterizada pelo processo de abertura política, a participação tornou-se pauta fundamental de reivindicação da saúde. Sua institucionalização obrigou, ao menos teoricamente, à democratização das políticas e serviços de saúde e do debate sobre esta.

Neste ensaio pretende-se abordar algumas questões sobre a busca e concretização da participação social no SUS. Para isso dialoga-se com pesquisadores que veem na participação uma forma de promover a equidade e de transformar a atenção à saúde. Nesse contexto, encara-se a participação como um objetivo a ser perseguido, porém não de forma cega e acrítica, é necessário constantemente refletir como tem ocorrido para que seja avaliada e aprimorada, tornando-se abertura real do sistema de saúde à população.

Tomou-se o conceito de Valla (1998, p. 9) para participação social, compreendendo "as múltiplas ações que diferentes forças sociais desenvolvem para influenciar a formulação, execução, fiscalização e avaliação das políticas públicas e/ou serviços básicos na área social”.

Como premissa para discutir sobre participação social, foi feita uma reflexão sobre a formação dos sujeitos coletivos e a construção da cidadania, considerando esses elementos como fundamentais para 
a conquista de espaços democráticos e de direitos sociais.

A normatização atual referente à participação popular foi analisada, procurando-se ressaltar os avanços que trouxe e as questões para as quais a abordagem mantém-se superficial e vaga, constituindo alguns dos pontos frágeis da participação.

Nesse contexto institucional, destacam-se elementos necessários para uma participação social efetiva. Os atores envolvidos com a questão da saúde passaram a ter maior contato entre si. As relações estabelecidas entre esses diferentes sujeitos, representantes do Estado ou dos diversos grupos da sociedade, são trabalhadas aqui como determinantes das decisões políticas. A forma como cada um defende os seus interesses coloca-os ora em posições opostas, ora como parceiros. Outro elemento importante da participação relaciona-se à essencialidade da comunicação, da informação e do conhecimento em saúde para a autonomia dos atores, tendo a educação em saúde como principal estratégia de ação.

Ao final, o presente ensaio dedica-se a problematizar o tema da participação social no SUS, trazendo à tona alguns dos obstáculos e críticas relativos ao assunto. É debatida a ideia de que os Conselhos e Conferências de Saúde sejam as formas predominantes de participação da sociedade na saúde. Essas instâncias representam experiências concretas de gestão participativa que trouxeram melhorias nesse campo no País e servem de exemplo de democratização do sistema de saúde. Porém a participação social para construir o SUS vai além desses espaços. Conselhos e Conferências não bastam para contemplar a diversidade de opiniões da sociedade em toda a sua complexidade de atores, tornando-se insuficientes quando representam a única abertura da gestão à participação popular.

Existem problemas estruturais e políticos que dificultam a organicidade de Conselhos e Conferências. Principalmente no âmbito municipal, há, em geral, baixa representatividade, pouca renovação de membros, dominação por grupos mais organizados, enfraquecimento da luta em outras frentes participativas e de comunicação (Dominguez, 2007).

Essas fragilidades democráticas e outras tensões relacionadas aos conselhos e conferências de saúde levam à necessidade de busca e valorização de ou- tras formas de participação que não estão tão bem definidas e nem são da mesma forma priorizadas. 0 processo de participação democrática constitui-se também por iniciativas de caráter coletivo e individual, como conselhos locais ou conselhos gestores, fóruns de trabalhadores, Ministério Público, ouvidorias, gestão participativa, pressão popular sobre o Congresso, e até a judicialização da saúde pode ser compreendida como um tipo de controle social, entre outros.

Dessa forma pretende-se contribuir para a reflexão sobre a participação e a organização do SUS, visando a real democratização dos espaços de escuta da sociedade civil, tornando-os locais cada vez mais apropriados para as tomadas de decisão sobre a construção de políticas e serviços de saúde, dos quais a população se apropria coletivamente superando a simples obrigatoriedade burocrática da participação e contribuindo para uma saúde pública gratuita e de qualidade para todos.

\section{A Construção da Cidadania e a Formação de Sujeitos Coletivos: fundamentos para a participação social em saúde}

Falar em participação social nos remete ao conceito de cidadania e de direitos sociais. Lembramos de valores de uso coletivo, do papel do Estado e da relação Estado/Sociedade. A reflexão sobre todos esses processos é pressuposto para uma sociedade democrática.

Para se pensar em cidadania e na relação Estado/ Sociedade, um tópico relevante é a constituição dos sujeitos coletivos. É preciso abordar as manifestações dos sujeitos políticos que se realizam através dos movimentos sociais (Nunes, 1995). A formação dos sujeitos coletivos é condicionada pelos processos históricos, políticos, sociais, econômicos e culturais. O processo histórico do Brasil, caracterizado por um longo período como colônia, império e ditadura, fundamenta a pouca experiência da sociedade com a democracia e a concepção de cidadania, determinando a formação política e cidadã dos brasileiros.

Mesmo numa sociedade carente de maturidade política, a busca por melhores condições sociais 
está presente, é algo que se dá numa concepção dialética, de forma simultânea ao estabelecimento da precariedade, mas condicionada às possibilidades de cada momento histórico. Da mesma maneira, a existência de um Estado pressupõe a existência de tensões na relação Estado-sociedade, principalmente, devido ao Estado ser, em princípio, um aparato da classe dominante para a manutenção da ordem (Canesqui, 1995).

Hoje, no Brasil, apesar da democracia política tão almejada, convive-se com uma grande desigualdade social e péssimas condições de vida. Essa situação leva a uma descrença no Estado e em qualquer possibilidade de mudança, fato que, conciliado a valores neoliberais incorporados pela sociedade, cria uma visão imobilizadora que tende a reproduzir as injustiças e não transformá-las. Outra questão que abala significativamente a possibilidade da constituição dos sujeitos sociais são as políticas públicas neoliberais de caráter compensatório e não preventivo e redistributivo, focal e não universal (Stotz, 1995).

A participação da sociedade civil em reivindicações e mobilizações políticas é voluntária, e, muitas vezes, não há para isso suporte estrutural ou mesmo incentivo moral (Serapioni e Romaní, 2006). Essa questão, somada à falta de tempo dos cidadãos, em meio a um sistema capitalista que promove valores individuais e restringe a sociedade ao consumo e à acumulação, além da frustração pelo não reconhecimento da importância da ação social política, configuram importantes obstáculos para a mobilização social.

A sociedade desigual em que vivemos leva à desestruturação do conceito de cidadania, ou seja, o sentido dado à cidadania é diferente de acordo com a condição social, a situação de trabalho, o pertencimento a sistemas de seguridade social (Stotz, 1995). Dessa forma, Valla e Stotz (1994) propõem duas categorias para cidadania, segundo a condição de reprodução social de camadas ou de grupos sociais: "cidadania de vigilância", quando serviços básicos já existem e a população precisa apenas vigiar para que continuem, e "cidadania de escassez", referente às populações que precisam estar continuamente pressionando e lutando politicamente para garantir serviços básicos que são tidos como concessões do Estado.
A partir dos anos 1970, surgiram diversos movimentos sociais no Brasil, e muitas das lutas elegeram a saúde seu objeto de reivindicações (Ribeiro, 1989; Stotz, 1995). Uma circunstância de transição se caracteriza pela incerteza e tensão, mas possibilita mudanças (Pêgo, 1993). O fim do regime militar renovou a utopia de uma sociedade democrática e justa, incentivando mobilizações e buscas por alternativas diante das concepções vigentes de cidadania.

Para Contandriopoulos (1995), uma forma de fomentar a mobilização é construir uma Utopia, como uma forma de visualizar os objetivos aos quais se quer chegar. A Utopia facilitaria a apreensão no ideário das pessoas de que os objetivos proclamados seriam viáveis. Dessa forma, a Utopia ajuda a agregar as forças sociais favoráveis à transformação.

No processo de redemocratização do País nos anos 1980, os movimentos sociais, como o Movimento de Reforma Sanitária, foram determinadores da maturação de um novo sujeito social brasileiro, consciente dos conceitos de sociedade e de cidadania e da importância de sua prática cotidiana para transformação da realidade (Pêgo, 1993).

Hoje os movimentos sociais são muitos e diversos. Consequência, dentre muitos fatores, do processo histórico de amadurecimento da cidadania e construção da democracia, da diversidade do País e de interesses dos distintos atores. Esses diversos movimentos sociais expressam diferentes formas de luta, de acordo com as dificuldades para a reprodução social da vida que os atores enfrentam nos ambientes físico, político e cultural em que estão imersos.

Para Lúcia Ribeiro (1989), o surgimento de um movimento social está atrelado à construção de uma identidade social. Esta se baseia numa dimensão estrutural, referente às condições objetivas da situação de carência e exclusão, e na dimensão cultural, ou seja, o reconhecimento da situação de precariedade (tomada de consciência coletiva) e a percepção da possibilidade de busca cotidiana por melhores condições que aos poucos vão constituindo valores sociais e uma visão de mundo, formando sujeitos de sua própria história.

No setor saúde, as condições objetivas predisponentes de mobilizações são: sistema de saúde 
com cobertura insuficiente e qualidade precária e diferenças nas condições de saúde segundo a classe social. A tomada de consciência dessa situação, o reconhecimento da possibilidade de enfrentá-la, o compartilhamento da história pessoal com outros indivíduos (construção de identidade), o sentido de pertencimento e a participação comunitária levam às ações transformadoras. A resistência brota da própria necessidade que as pessoas têm de sobreviver, de não serem oprimidas pelo cansaço, pela doença e pelo poder hegemônico (Valla e Stotz, 1994). Assim, surge a politização de demandas, na qual a saúde passa a ser vista como um direito social, as reivindicações, e também a construção de princípios relacionados ao conceito ampliado de saúde, à gratuidade, à equidade e à participação ampla nas decisões. Dessa forma, a consciência sanitária colabora na ampliação dos limites da cidadania, configurando-se como causa e consequência de uma consciência social (Valla e Stotz, 1994).

Uma fragilidade de muitos dos movimentos sociais é a restrição de suas decisões, práticas e reivindicações a demandas desconectadas de um projeto global de sociedade (Ribeiro, 1989). Conquistas imediatas podem ser mobilizadoras de um movimento popular, mas é preciso amadurecer os objetivos buscados para lutar por conquistas mais abrangentes, pois quando as possibilidades de ganhos imediatos diminuem, o grupo tende a esvaecer.

Seguindo apenas uma consciência imediata e superficial dos problemas sociais, as revoltas e manifestações populares estão arriscadas a seguirem a lógica da aceitação do modelo, lutando apenas para incluir-se nele e não para transformá-lo (Valla e Stotz, 1994). O investimento teórico junto do contato com a realidade amplia o espaço de luta para além das instituições, tornando a sociedade o principal objeto para transformação.

No complexo cenário da saúde, que envolve inúmeros atores, é preciso reconhecer que cada um ocupa uma posição diferente, singular e importante. Não se deve tentar traçar uma relação hierárquica entre essas posições e sim perceber a necessidade de troca e cooperação (Valla e Stotz, 1994). A interface dos movimentos populares com outros atores, como os profissionais de saúde, partidos políticos, igrejas, Estado, favorece maiores conquistas, pois integra saberes e forças em saúde, e permite a construção de um novo conhecimento/saber.

Nessas parcerias, as contribuições do movimento popular são suas experiências, aspirações e valores adquiridos os quais são enriquecidos e modificados na relação, por exemplo, com profissionais de saúde que podem agir como educadores, facilitadores e mobilizadores, mesmo sendo, de acordo com Valla (1998), inevitável em alguns momentos a dificuldade de compreensão entre estes. Bodstein (1993) sublinha que o nível local é um espaço privilegiado para constitui-se atores e construir identidades coletivas, pois é palco de questões concretas sobre saúde e da interação entre agentes sociais.

É possível apontar duas questões primordiais para se pensar em mobilização popular pelo direito à saúde. A primeira é superar a visão de que as ações públicas em saúde são como concessões/benesses/ favores do governo à população e não um direito (Valla e Stotz, 1994). Tarefa difícil para nossa sociedade tão acostumada às práticas de clientelismo. A segunda questão também depende de superar uma visão, de que a saúde é uma responsabilidade individual. É preciso compreender a inter-relação dos processos saúde-doença com a dinâmica da sociedade. Sendo assim, as causas dos problemas de saúde escapam ao controle dos indivíduos (Valla e Stotz, 1994). As soluções precisam ser buscadas no coletivo, considerando que, como afirmam Valla e Stotz (1994, p. 140), muitas vezes a "efetivação dos direitos sociais para todos implica inclusive em restringir alguns direitos individuais".

O processo de luta pelo direito à saúde é um exemplo claro da formação de atores sociais, simultâneo à construção e ampliação da cidadania.

No início do século XX, o direito à saúde foi colocado na agenda pública na forma de assistência médica e serviços hospitalares como políticas sociais. Isso ocorreu não somente devido aos interesses capitalistas de reprodução da força de trabalho e de transformação da saúde em bem de consumo; também não foi devido apenas ao ato de consolidar a instituição médica por meio da priorização da ciência e tecnologia que favoreceu a cultura da medicalização. A oferta de recursos médico-assistenciais pelo Estado brasileiro deve ser analisada também como resposta a uma demanda social legítima, 
mesmo esta não respondendo satisfatoriamente à maioria da população (Bodstein, 1993).

0 direito à saúde evoluiu significativamente com a concepção ampliada de saúde-doença trazida pelo Movimento de Reforma Sanitária. Novas práticas, além da assistencial, foram englobadas ao cuidado com a saúde e também passaram a ser dever do Estado. $\mathrm{O}$ direito à saúde para além dos consultórios passou a integrar as reivindicações populares. A descentralização foi vista como uma aproximação entre poder e população, dando condições para construção da democracia e permitindo desenvolver os princípios fundamentais da cidadania (Bodstein, 1993). Porém consolidar essas conquistas do plano legal e transformá-las em conquistas reais no cotidiano da sociedade brasileira é um grande desafio.

\section{O Ambiente Institucional da Participação Social}

\section{Histórico da normatização da participação social no SUS}

O SUS foi instituído na Constituição Federal de 1988 e desde seu nascimento legal é organizado, dentre outras, pela diretriz da participação social (Brasil, 1988). As leis orgânicas reafirmam e dão maior detalhamento à diretriz de participação. A Lei 8.080/9o (Brasil, 1990a) explicita esse princípio e traz a ideia de controle social.

A Lei 8.142/9o (Brasil, 199ob) dispõe sobre a participação da comunidade na gestão do SUS, definindo as instâncias colegiadas, Conferência de Saúde e Conselho de Saúde. Ambos com regimento próprio, a primeira, com periodicidade de quatro anos, é composta por diversos segmentos sociais, deve avaliar a situação de saúde e propor diretrizes. Os conselhos têm caráter permanente e deliberativo, devem formular estratégias e controlar amplamente a execução de políticas, são compostos por $50 \%$ de usuários e a outra metade dividida entre representantes do governo, prestadores de serviço e profissionais da saúde. Essa lei também vincula a transferência de recursos à existência dos conselhos de saúde em cada esfera.

O Conselho Nacional de Saúde (CNS) existe desde 1937, mas até 1990 era um órgão consultivo do
Ministério e seus conselheiros eram indicados pelo governo. De 1990 até 2006, a organização e competências do CNS foram alteradas, aproximando-o da legislação do SUS (CNS, s.d.). Hoje o CNS é composto por quarenta e oito membros titulares, cada um com dois suplentes, indicados pelas entidades eleitas a cada três anos. A composição segue a paridade estabelecida na Lei 8.142/9o, sendo cinquenta por cento formada por representantes de entidades e dos movimentos sociais de usuários do SUS; e cinquenta por cento, representantes de entidades de profissionais de saúde, incluída a comunidade científica, representantes do governo, entidades prestadoras de serviços, Conselho Nacional de Secretários de Saúde - CONASS, Conselho Nacional de Secretários Municipais de Saúde - CONASEMS e entidades empresariais com atividade na área de saúde (Brasil, 2006a).

A Resolução 333, de 04 de novembro de 2003 (Brasil, 2003) do Conselho Nacional de Saúde estabelece as recomendações e diretrizes para criar, estruturar, reformular e também para o funcionamento dos conselhos estaduais e municipais de saúde. Nessa resolução são consideradas as ampliações dos conselhos de saúde, como os Conselhos Regionais, Conselhos Locais, Conselhos Distritais de Saúde, incluindo os Conselhos Distritais Sanitários Indígenas, sob a coordenação dos Conselhos de Saúde da esfera correspondente. Ainda de acordo com esse documento, a criação dos conselhos e o número de conselheiros são definidos pela lei de cada ente federado e o presidente deve ser eleito por seus membros. As vagas de conselheiros devem ser distribuídas de forma paritária. São dados critérios e exemplos para as representações, além da sugestão de mandatos com duração de dois anos e os motivos para substituição de conselheiros. 0 documento também direciona a formação e o funcionamento da estrutura administrava dos conselhos, das comissões e as competências do plenário, sendo o governo responsável por garantir a dotação orçamentária e autonomia do conselho.

Nos anos 1990, os instrumentos de regulamentação utilizados para o avanço dos processos de rompimento com o antigo modelo de saúde, centralizado e verticalizado, e de construção do SUS foram as Normas Operacionais Básicas (NOB).

As NOB 93 e 96 e a NOAS definem um número 
maior de requisitos, em relação aos instrumentos anteriores, para a habilitação de municípios e Estados nas diferentes condições de gestão. Porém, no que se refere à participação da comunidade, princípio fundamental do sistema de saúde assim como a descentralização e a regionalização, essas normas exigem apenas que se comprove o funcionamento dos conselhos de saúde. Elas buscam o avanço da administração técnica e são incipientes para construirem uma gestão participativa efetiva (Brasil, 1993, 1996, 2002; Levcovitz e col., 2001).

Em 2006, foi publicado o Pacto pela Saúde (Brasil, 2006b). De seus três componentes, o Pacto em Defesa do SUS, por abordar a busca pelos princípios basilares do sistema de saúde, é o mais voltado para a participação social. Isso fica claro nas suas prioridades de busca pela repolitização da saúde, como estratégia de mobilização social, e pelo avanço no processo de institucionalizar a saúde como direito de cidadania, além de se elaborar e divulgar a Carta dos Direitos dos Usuários do SUS. Dentre as ações do Pacto em Defesa do SUS, encontram-se o estabelecimento de diálogo com a sociedade, além dos limites institucionais, e fortalecimento das relações com os movimentos sociais. O Pacto de Gestão também aborda esse tema ao reiterar a importância da participação e do controle social, fazendo deles diretrizes da gestão do SUS e comprometendo-se com sua qualificação. A existência de um sub-bloco de financiamento específico para participação e controle social e a explicitação das responsabilidades de cada esfera de gestão relativas a essa dimensão do SUS promovem o fortalecimento dos espaços e mecanismos onde ela se dá.

A Carta dos Direitos dos Usuários da Saúde (Brasil, 2006c) foi criada com a intenção de informar ao cidadão sobre os seus direitos e deveres como usuário do SUS. Ela é um esclarecimento de seis princípios de cidadania destacados a partir da legislação. A maioria desses princípios relaciona-se ao atendimento médico. Quanto à participação e ao controle social, o documento declara o direito de acesso às devidas instituições onde podem ser feitas sugestões, reclamações e denúncias, além do direito de participar de conferências, conselhos de saúde e conselhos gestores, seja como representante, seja indicando seus representantes.

Reconhecendo-se a gestão participativa como uma das estratégias transversais para a consolidação do SUS, foi criada em 2003 a Secretaria de Gestão Estratégica e Participativa - SGEP, tendo como primeiro secretário o sanitarista Antônio Sérgio da Silva Arouca, um dos construtores do ideário da Reforma Sanitária brasileira².

A SGEP foi responsável por formular a política nacional de gestão estratégica e participativa no SUS (PNGEP) - PARTICIPASUS (Brasil, 2007). Segundo essa política, a SGEP tem a responsabilidade de "acelerar e aperfeiçoar a implementação das práticas de gestão estratégica e participativa nas três esferas de gestão do SUS”.

A PNGEP ressalta, no âmbito da gestão participativa, a importância de práticas e mecanismos que formulem e deliberem coletivamente políticas em saúde e considera como um desafio efetivar a participação popular, que deve ser alcançada por meio da ampliação de espaços públicos e coletivos para o exercício do diálogo e da pactuação das diferenças. Quanto à ouvidoria, a política propõe a criação de alternativas eficientes de informação e de escuta da população, além de aumentar a divulgação das prestações de contas e dos relatórios de gestão como uma forma de fomentar a gestão do SUS. Em relação à auditoria, há uma preocupação com o acompanhamento dos serviços de saúde, das ações preventivas, da qualidade de assistência e da gestão de análise dos resultados, contribuindo para a garantia do acesso e da atenção aos usuários e em defesa da vida. Por fim, o monitoramento, avaliação e controle da gestão do SUS são tidos como uma forma de qualificação da gestão do sistema e como importante eixo para integração de todos os outros (Brasil, 2007).

A política divide as ações de gestão participativa em sete tipos: mecanismos institucionalizados de controle social, processos participativos de gestão, instâncias de pactuação entre gestores, mecanismos de mobilização social, processos de educação popular em saúde, reconstrução do significado da educação em saúde, ações articuladas entre dife-

2 Outras informações sobre a SGEP, acesse: http://portal.saude.gov.br/portal/saude/Gestor/visualizar_texto.cfm?idtxt=26599\&janela=1 
rentes setores de governo e a sociedade civil (Brasil, 2007).

As ações a serem desenvolvidas explicitadas na política em relação ao aprimoramento das instâncias e processos de participação social no SUS abordam a realização e fortalecimento das conferências e dos conselhos de saúde, mas são muito vagas quanto aos outros mecanismos de participação política direta na formulação e encaminhamento de políticas de saúde. Dentre essas ações, é citada a busca por novos canais de escuta da população, mas não garante a força dessas falas nos efetivos processos de construção do SUS.

\section{Elementos da participação social no sistema de saúde brasileiro}

Participação política da sociedade significa que ela mesma defina o que deve ou não ser objeto de políticas públicas e os rumos que essas políticas irão tomar. Essa concepção diverge de outra forma de orientação da sociedade, na qual setores com recursos e hegemonia apontam o caminho a ser seguido pelas classes populares (Valla, 1998).

A participação é determinante fundamental da democracia. Não é concessão nem exigência burocrática, mas uma conquista social. Participação plena significa decidir, acompanhar e avaliar a organização dos serviços, ou seja, exercer o controle social. Ela se constitui de forma politizada e permite que um coletivo decida sobre assuntos de interesse geral. Assim, as diferentes realidades da população podem ser contempladas na construção de políticas. Para isso o debate amplo e intenso torna-se essencial e as disputas são inevitáveis.

Santos Filho e Gomes (2007) afirmam que o maior fomento à participação comunitária pelos governos locais deve-se à obrigatoriedade legal, à assinatura de acordos internacionais comprometendo-se a firmar parcerias com a comunidade e à percepção dos gestores de que as políticas são mais eficientes quando a população está envolvida.

Comparando modelos de participação em saúde da Itália, Inglaterra e Brasil, Serapioni e Romaní (2006) afirmam que o fato de países tão diferentes buscarem por participação social deve-se às mudanças na relação Estado/sociedade e à percepção que esse é um fator fundamental para a qualidade de vida, porém sua prática ainda é incipiente, pois existe uma dificuldade de estruturação desse conceito. Os Comitês Consultivos Mistos (CCM) italianos, formados por associações da sociedade civil, profissionais e administradores, são órgãos que apenas sugerem mudanças nos serviços de saúde. Estes comitês são vistos de forma positiva por permitirem o entendimento entre os diferentes atores. Os Conselhos Comunitários de Saúde (CHC) da Inglaterra existem desde 1974, são formados exclusivamente por representantes dos usuários escolhidos de diversas formas e têm caráter controlador/ vigilante do sistema de saúde. Essa composição pode representar uma perda em interação entre diferentes atores, mas ganha em autonomia. Os Conselhos Municipais de Saúde brasileiros diferenciam-se dos demais principalmente por seu caráter deliberativo previsto na legislação.

Os canais institucionais de cogestão com o Estado por si representam apenas um potencial democrático. A busca sistemática das referências que se dedicam a estudar o exercício da participação popular no SUS permite levantar alguns dos elementos relevantes para a participação tornarse um processo realmente vantajoso à população. Existem requisitos a serem cumpridos pelo Estado e pela população que vão além da institucionalização legal, além do acesso dos agentes sociais ao processo decisório.

Imprescindível para a participação, segundo Pêgo (1993) é diminuir a distância entre sociedade e política, compreendendo esta como algo constante na vida de todos. Só assim entende-se que políticas públicas não são iniciativas exclusivas do aparelho estatal, mas fruto de interlocução e pactuação entre atores sociais com diversidade de interesses e necessidades.

O fato de institucionalizar a participação promoveu a inclusão de uma série de novos atores no debate da saúde, ampliando seus poderes para reivindicações e também sua responsabilidade sobre a definição de questões ligadas à área.

Considerando a heterogeneidade da população e o caráter da relação Estado-Sociedade, a configuração das políticas públicas é resultante das forças sociais em luta pela hegemonia (Pêgo, 1993). Os diferentes grupos sociais constroem projetos dis- 
tintos e, às vezes, contraditórios, em que cada um busca impor a sua perspectiva na esfera decisória política.

Atualmente existe uma clara diferenciação e fragmentação da demanda social por saúde, o grupo mais pobre e, portanto, com pouca organização e força política, lutando pelo serviço público de saúde e um outro grupo social, politicamente melhor estruturado, reivindicando planos de saúde privados. Essa desigualdade de forças e projetos entre grupos sociais relaciona-se à estrutura social do capitalismo que separa a população em classes, situação que afeta a capacidade de expressão política de cada grupo (Stotz, 1995).

A capacidade de um grupo social impor suas demandas nas pautas de negociação, ou seja, ter assegurado pelo Estado o enfrentamento de seus problemas por meio de políticas públicas, depende da conjuntura política e econômica. Contudo também é importante nesse processo formar sujeitos coletivos, constituindo-se autonomamente na esfera política para integrarem a base de sustentação e imporem projetos contrários ao do capital.

A autonomia dos movimentos populares nas relações com o Estado é essencial, só assim é possível avaliar, fiscalizar e apresentar mudanças quanto aos serviços e políticas públicas sociais (Valla e Stotz, 1994). A participação social efetiva necessita que haja o direito de exercer oposição. Para avaliar a participação social é preciso considerar o grau de contestação pública ou competição política existente. De acordo com Perissinotto (2002), se não houver debate, conflito, publicização das questões, alternância no comando da instituição, a participação pode traduzir-se em aclamação ou em decisão sobre assuntos de menor importância ou ainda em discussão sobre "objetivos predefinidos".

Formas avançadas de proteção social expressam maior capacidade de organização e de pressão da sociedade (Bodstein, 1993). Da mesma forma, a saúde é um direito social cuja expressão depende do grau de consciência e de organização das classes e grupos sociais.

Nessa arena de disputa, que representa o setor saúde, um fator responsável por desequilibrar as forças é o acesso à informação e ao conhecimento. A difusão de informações e de conhecimentos é essen- cial para incitar a luta pelo direito social à saúde e a uma vida digna. Esse ponto também é importante tanto para a construção de atores e de uma identidade coletiva, quanto para estruturar, solidificar e renovar um movimento social.

É necessária a comunicação entre os diferentes setores e segmentos da sociedade para se reconhecer e considerar as divergências e semelhanças entre os grupos sociais. Para Oliveira (1996) o exercício da alteridade melhora a relação e comunicação entre os seguimentos. Avanços são alcançados quando há uma diversidade de olhares e espaços de articulação entre Estado/sociedade, sociedade/sociedade e Estado/Estado, pois se aproxima das diversas realidades e encontram-se soluções mais concretas, adequadas e viáveis.

Portanto a comunicação como um processo dialógico é fundamental ao controle social. Por isso é importante assegurar o acesso adequado e suficiente às informações produzidas pelo SUS e o direito de cada um se expressar, ser ouvido e considerado.

O conhecimento contribui para a tomada de decisões, sem ele não há como a população organizada exercer o seu papel de fiscalizadora e avaliadora dos serviços, e consequentemente de conseguir a melhoria real de sua saúde. Por isso a comunicação está relacionada ao poder, e sua apropriação pelas camadas populares é um importante instrumento de luta contra a hegemonia, retirando a população do papel de refém do saber técnico.

Formar constantemente os atores envolvidos no controle social por meio de ações de educação em saúde amplia a capacidade da população de vocalizar suas necessidades e desejos. Essas ações colaboram na formação política, aumentando a efetividade do controle social sobre as políticas públicas através da politização dos movimentos e práticas populares.

Para Westphal (1994), o processo educativo se dá com a participação ativa dos sujeitos em dois momentos: a aprendizagem pela prática da luta social em contato com o Estado e sua burocracia; e a aprendizagem formal por meio de cursos que propiciem formação política, acesso a informações e conhecimentos, colaborando na interpretação crítica da realidade.

Benzaken e colaboradores (2007) mostraram que a cooperação da sociedade junto de outros atores, 
desde a construção dos programas políticos até a avaliação, mantém a população envolvida e permite a sustentabilidade da ação, partindo do princípio que as questões da saúde estão além da atmosfera técnica, passam por fatores culturais e políticos. Também se afirma que, de forma dialética, a participação e a mobilização social tornam-se reciprocamente causa e consequência, construindo a identidade social que fortalece o coletivo.

\section{Dilemas e Desafios da Participação Institucional no SUS}

Hoje uma grande parcela da participação social se dá através dos espaços institucionais, fato que exige uma análise criteriosa. A amplitude do poder deliberativo desses espaços é limitada pelas fragilidades práticas dos órgãos. A participação prevista na legislação não é, necessariamente, a garantia de participação no cotidiano do sistema. A conquista de representação popular nos espaços deliberativos é sem dúvida um avanço, porém deve-se questionar se a ação institucional que os movimentos sociais privilegiam tem permitido a construção de um efetivo controle social dos serviços de saúde (Valla e Stotz, 1994).

Segundo Gastal e Gutfreind (2007), para a participação ativa da população é necessária a percepção da saúde como um direito. Para eles a obrigatoriedade institucional da participação torna-a menos efetiva se comparada à participação socialmente construída, além de experiências coletivas serem mais propícias para a formação de sujeitos.

A participação popular pode servir simplesmente como uma forma de legitimar a política de Estado diante da população (Valla, 1998). É uma distorção da participação e serve para adequar o discurso participativo às antigas formas de exercer o poder (Oliveira, 1996).

Santos Filho e Gomes (2007) notaram a resistência de instituições governamentais em trabalhar com os novos atores sociais, o que se deve à falta de prática nesta forma de gestão e, de acordo com Oliveira (1996), a uma concepção de gestores e profissionais de que o usuário seria incapaz de contribuir. Guizardi e Pinheiro (2006) também afirmam a dificuldade de intervenção nas políticas pelo setor popular apesar da participação instituída. Essa pouca influência nas decisões, segundo Serapioni e Romaní (2006), possivelmente se deve a uma sociedade ainda politicamente imatura ou a um sistema de saúde ainda fechado para o ambiente social.

Oliveira (1996) também chama a atenção para o quão etnocêntrica é a participação institucionalizada. Esses espaços são criados à maneira de gestores e profissionais, a população depois é convidada a compô-los e a aderir a uma cultura, muitas vezes, estranha às culturas dos diferentes grupos sociais. Os segmentos detentores de conhecimento e capacitação têm maior peso nas decisões, impõem uma linha técnica à discussão e excluem os não familiarizados ao jargão científico (Serapioni e Romaní, 2006).

Além da posição de desvantagem dos usuários nos conselhos, aqueles ainda não contam com disponibilidade de tempo, transporte, assessoria institucional, enfim, toda uma infraestrutura que geralmente está presente para a participação dos demais segmentos.

Outro questionamento importante está relacionado à forma como o Estado responde de modo mais favorável àqueles grupos mais organizados e familiarizados à burocracia pública (Valla e Stotz, 1994). Dessa forma a institucionalização dos mecanismos de participação pode se tornar instrumento de manutenção das relações de poder na sociedade, pois os mais organizados são favorecidos e os menos organizados, mais vulneráveis, são mantidos assim.

Uma situação que também se torna obstáculo significativo no tema da participação institucionalizada é a disputa de projetos e por assento nos conselhos entre as muitas organizações populares existentes (Bodstein, 1993). Essa situação cria um clima de conflito dentro do próprio segmento, além daquele já existente com os outros segmentos componentes dos conselhos de saúde. Os pontos de divergência são supervalorizados no cenário institucional e as semelhanças nas lutas de cada entidade, muitas vezes, são negadas. Isso dificulta a construção de agendas comuns dos movimentos populares para a articulação de lutas políticas e institucionais visando o acesso de todos a bens, serviços e direitos sociais.

Além da existência dos conselhos de saúde de- 
pender da vontade do gestor, a reprodução dos procedimentos administrativos estatais implica numa forte dependência das entidades representativas populares perante o Estado (Valla; Stotz,1994). Existe a probabilidade de essas entidades passarem a ser vistas e agirem como um poder local do Estado.

Os conselhos e conferências de saúde são nitidamente priorizados nos textos oficiais e também pela maioria dos atores sociais. Adotados praticamente como as únicas formas de partilha de poder de decisão entre gestores, trabalhadores e usuários do SUS, muitas vezes esses espaços são encarados de forma pouco reflexiva, impedindo avanços no controle social.

A maioria dos conselhos municipais de saúde brasileiros enfrenta problemas estruturais e políticos que dificultam sua organicidade e autonomia. Há dificuldades quanto à falta de paridade, representatividade, orçamento próprio e autonomia no gerenciamento de recursos, alguns não possuem sede ou linha telefônica própria, além da informatização e acesso à internet não fazer parte da realidade de muitos (Dominguez, 2007). Essas questões explicitam o comum não cumprimento da Resolução do CNS n- 333/o3 (Brasil, 2003).

O processo de escolha de representantes para os espaços institucionais de decisão em saúde influencia a credibilidade destes. A representação é uma forma de participação que possui importantes limitações. Ela se torna frágil quando o grupo representado está fragmentado e não há mecanismos que propiciem o debate. São necessárias formas adequadas para a escolha do representante e para a comunicação direta entre ele e seus representados. O aumento do vínculo com a base legitima a representação e aumenta a força política.

De acordo com a Resolução 333/03 (Brasil, 2003), os membros dos conselhos de saúde são escolhidos para representar a sociedade como um todo, mesmo assim, geralmente, cada organização procura que seus próprios membros se tornem os conselheiros. Tal fato levanta o debate sobre a que interesses o conselheiro está vinculado: interesses gerais ou particulares, além de quem e de que forma o conselheiro representa (Bodstein, 1993). As marcas indeléveis da cultura do clientelismo e paternalismo, presentes na história do País, geram a ideia de que a posição de representante pode trazer algum privilégio para o grupo específico que representa (Bodstein, 1993). É natural que um conselheiro leve as reivindicações de seus pares, mas estas não podem ser mais importantes que as do conjunto.

Outra distorção na construção de um projeto de saúde baseado em valores democráticos e justos para Bodstein (1993) é a interferência de pressões de outros atores na pretensão de usar a força de um movimento popular para seus interesses próprios. Para que essa forma de cooptação não ocorra, a população deve estar organizada e sua participação em conselhos e conferências bem embasada e atrelada às necessidades em saúde.

Todas essas questões tornam polêmica a participação social institucionalizada. Também polêmico é o discurso da participação social na política de promoção da saúde. Carvalho (2004) traz a discussão das múltiplas interpretações do chamado empowerment, que pode ser uma forma de promover a sensação de controle do indivíduo sobre o processo saúde-doença sem que sejam necessárias transformações no modo de produção vigente e nas relações sociais, ou significar o que esse autor chamou de "empowerment comunitário", objetivando maior justiça social que se dá através da divulgação/ popularização de informações sobre saúde e seus determinantes, desenvolvimento da consciência crítica e o aumento da capacidade de intervenção sobre a realidade.

Esses problemas e questionamentos quanto à participação social institucionalizada não são exclusividade brasileira, Serapioni e Romaní (2006) também reconhecem muitos deles nos espaços de participação social de outros países, como CCM da Itália e CHC da Inglaterra.

Espaços institucionalizados de participação popular contribuem para formar identidades coletivas por meio da dimensão política. Mas não podem ser esquecidas as formas de luta próprias dos movimentos sociais, que também provocam os sujeitos a se mobilizarem e lutarem para atender suas carências vividas e sentidas coletivamente. A restrição do campo de reivindicação aos espaços institucionalizados torna os movimentos populares vulneráveis 
e obedientes ao aparelho estatal, por isso é preciso impedir que ocorra o enfraquecimento da luta em outras frentes de participação e comunicação (Bodstein, 1993). É necessário ampliar o conceito de participação e seus arranjos políticos para que não se perca a riqueza do pensamento popular dentro dos padrões do sistema (Feuerwerker, 2005).

\section{Considerações Finais}

Quando se adota o conceito ampliado de saúde, a participação social torna-se condição sine qua non para seu exercício pleno. Não se pode considerar saudável uma população alijada do processo de decisão sobre os rumos da saúde pública, por isso uma das bandeiras defendidas pelo Movimento de Reforma Sanitária foi a institucionalização da participação.

O envolvimento da população permite a ela se apropriar de sua saúde e conduz à formação da consciência sanitária que se estende às demais questões sociais. Nesse processo, alcança-se amadurecimento político e ampliação da cidadania, essenciais ao desenvolvimento de uma sociedade justa e distante das tradicionais práticas opressivas de poder.

A decisão política institucional de fortalecer a participação social na gestão das políticas de saúde deve ser valorizada de acordo com sua potencialidade em permitir avanços na universalização e na equidade do acesso à saúde, além de ser uma forma de qualificação da gestão pública. A abertura da gestão aos diversos olhares e vozes democratiza e compatibiliza as ações em saúde pública às reais demandas sociais.

A reflexão crítica e constante sobre a praxis da participação popular não pode em momento algum ser abandonada. É preciso não esquecer o que representa em nossa sociedade atual o exercício do poder.

Retomando o conceito de participação social de Valla (1998), as "múltiplas ações" das "diferentes forças sociais" são relevantes e se complementam. A prática institucional não substitui as conhecidas formas de pressão política dos movimentos sociais. Ela se soma às demais manifestações dos sujeitos coletivos em busca de saúde e qualidade de vida.

\section{Referências}

BENZAKEN, A. S. et al. Intervenção de base comunitária para a prevenção das DST/Aids na região amazônica, Brasil. Revista de Saúde Pública, v. 41, p. 118-26, 2007. Suplemento 2.

BODSTEIN, R. C. A. (Org.). Serviços locais de saúde: construção de atores e políticas. Rio de Janeiro: Relume-Dumará, 1993.

BRASIL. Constituição (1988). Constituição da República Federativa do Brasil. Brasília, DF: Senado, 1988. Título VIII - Da Ordem Social. Seção II - Da Saúde. Arts. 196-20o.

BRASIL. Lei n 8.080, de 19 de setembro de 1990. Dispõe sobre as condições para a promoção, proteção e recuperação da saúde, a organização e o funcionamento dos serviços correspondentes e dá outras providências. Diário Oficial da União, Brasília, DF, 20 set., 1990a. Seção 1, p. 18055.

BRASIL. Lei n ${ }^{\circ} 8.142$, de 28 de dezembro de 1990. Dispõe sobre a participação da comunidade na gestão do Sistema Único de Saúde (SUS) e sobre as transferências intergovernamentais de recursos financeiros na área da saúde e dá outras providências. Diário Oficial da União, Brasília, DF, 31 dez., 199ob. Seção 1, p. 25694

BRASIL. Ministério da Saúde. Portaria nº 545 , de 20 de maio de 1993. Estabelece normas e procedimentos reguladores do processo de descentralização da gestão das ações e serviços de saúde, através da Norma Operacional Básica SUS o1/93. Diário Oficial da União. Brasília, DF, 24 maio, 1993. Seção 1, p. 6961.

BRASIL. Ministério da Saúde. Portaria nº 2.203, de 5 de novembro de 1996. Diário Oficial da União. Brasília, DF, 6 nov., 1996. Seção 1, p. 22932.

BRASIL. Ministério da Saúde. Portaria n 373 , de 27 de fevereiro de 2002. Diário Oficial da União.

Brasília, DF, 28 fev., 2002. Seção 1, p. 52.

BRASIL. Ministério da Saúde. Conselho Nacional de Saúde. Resolução ${ }^{0}{ }^{333}$, de 4 de novembro de 2003. Aprova as diretrizes para criação, reformulação, estruturação e funcionamento dos Conselhos de Saúde. Diário Oficial da União. Brasília, DF, 4 dez., 2003. Seção 1, p. 57. 
BRASIL. Decreto n ${ }^{0}$ 5.839, de 11 de julho de 2006. Dispõe sobre a organização, as atribuições e o processo eleitoral do Conselho Nacional de Saúde CNS e dá outras providências. Diário Oficial da União. Brasília, DF, 12 jul., 2006a. Seção1, p. 1.

BRASIL. Ministério da Saúde. Portaria nº 399, de 22 de fevereiro de 2006. Divulga o Pacto pela Saúde 2006 - Consolidação do SUS e aprova as Diretrizes Operacionais do referido pacto. Diário Oficial da União. Brasília, DF, 23 fev., 2006b. Seção 1, p. 43.

BRASIL. Ministério da Saúde. Carta dos direitos dos usuários da saúde. Brasília, DF: Ministério da Saúde, 2006c.

BRASIL. Ministério da Saúde. Política nacional de gestão estratégica e participativa no SUS ParticipaSUS. Brasília, DF: Ministério da Saúde, 2007.

CANESQUI, A. M. Ciências sociais, a saúde e a saúde coletiva. In: CANESQUI, A. M. (Org.). Dilemas e desafios das ciências sociais na saúde coletiva. São Paulo: Hucitec/Abrasco, 1995.

CARVALHO, S. R. Os múltiplos sentidos da categoria "empowerment" no projeto de promoção à saúde. Cadernos de Saúde Pública, Rio de Janeiro, v. 20, n. 4, p. 1088-1095, jul./ago. 2004.

CONSELHO NACIONAL DE SAÚDE - CNS. História do CNS. Brasília, DF: Conselho Nacional de Saúde, s/d. Disponível em: http://www.conselho.saude. gov.br/apresentacao/historia.htm. Acesso em 25 mar. 2008.

CONTANDRIOPOULOS, A. P. Reformar o sistema de saúde: uma utopia para sair de um status quo inaceitável. Saúde em Debate, Londrina, n. 49-5o, p. 53-64, dez./95-mar./96.

DOMINGUEZ, B. C. A gestão autoritária cede espaço, pouco a pouco, à práxis democrática.

RADIS Comunicação em Saúde, Rio de Janeiro, $\mathrm{n}$. 53, p. 12-19, jan. 2007.

FEUERWERKER, L. Modelos tecnoassistenciais, gestão e organização do trabalho em saúde: nada é indiferente no processo de luta para a consolidação do SUS. Revista Interface Comunicação, Saúde, Educação, Botucatu, v. 9, n. 18, p. 489-5o6, set./dez. 2005.
GASTAL, C. L. da C.; GUTFREIND, C. Um estudo comparativo de dois serviços de saúde mental: relações entre participação popular e representações sociais relacionadas ao direito à saúde. Cadernos de Saúde Pública, Rio de Janeiro, v. 23, n.8, p.1835-1844, ago. 2007.

GUIZARDI, F. L.; PINHEIRO, R. Dilemas culturais, sociais e políticos da participação dos movimentos sociais nos Conselhos de Saúde.

Ciência \& Saúde Coletiva, Rio de Janeiro, v. 11, n. 3 , p. 797-805, set. 2006.

LEVCOVITZ, E.; LIMA, L. D.; MACHADO, C. V. Política de saúde nos anos 9o: relações intergovernamentais e o papel das normas operacionais básicas. Ciência \& Saúde Coletiva, Rio de Janeiro, v. 6, n. 2, p. 269-291, 2001.

NUNES, E. D. As ciências sociais e a saúde: o pensamento recente de alguns pesquisadores. In: CANESQUI, A. M. (Org.). Dilemas e desafios das ciências sociais na saúde coletiva. São Paulo: Hucitec/Abrasco, 1995. p. 53-61.

OLIVEIRA, F. J. A. Participação popular em saúde: as dimensões da cultura. Saúde em Debate, Londrina, n. 52, p. 67-73, set. 1996.

PÊGO, R. A. Movimentos sociais na saúde e identidades coletivas (um estudo de caso). In: BODSTEIN, R. C. A. (Org.). Serviços locais de saúde: construção de atores e políticas. Rio de Janeiro: Relume Dumará, 1993. p. 63-95.

PERISSINOTTO, R. M. Democracia e participação: o caso do Conselho Municipal de Assistência Social de Curitiba. In: PERISSINOTTO, R. M.; FUKS, M. (Org.). Democracia: teoria e prática. Rio de Janeiro: Relume Dumará, 2002. v. 1, p. 211-244.

RIBEIRO, L. Os movimentos sociais e sua relação com a questão da saúde. Cadernos de Saúde Pública, Rio de Janeiro, v. 5, n. 3, p. 264-275, jul./ set. 1989 .

SANTOS FILHO, E. T. dos; GOMES, Z. M. dos S. Estratégias de controle da tuberculose no Brasil: articulação e participação da sociedade civil. Revista de Saúde Pública, São Paulo, v. 41, p.111116, 2007. Suplemento 1. 
SERAPIONI, M.; ROMANÍ, O. Potencialidades e desafios da participação em instâncias colegiadas dos sistemas de saúde: os casos de Itália, Inglaterra e Brasil. Cadernos de Saúde Pública, Rio de Janeiro, v. 22, n. 11, p. 2411-2421, nov. 2006.

STOTZ, E. N. Movimentos sociais e saúde: das dificuldades em incorporar a temática às inflexões teórico-metodológicas das ciências sociais. In: CANESQUI, A. M. (Org.). Dilemas e desafios das ciências sociais na saúde coletiva. São Paulo: Hucitec/Abrasco, 1995. p. 99-125.

VALLA, V. V. Sobre participação popular: uma questão de perspectiva. Cadernos de Saúde Pública, Rio de Janeiro, v. 14, p. 7-18, 1998. Suplemento 2.

VALLA, V. V.; STOTZ, E. N. (Org.). Educação, saúde e cidadania. Petrópolis: Vozes, 1994. p. 142.

WESTPHAL, M. F. Movimentos sociais e comunitários no campo da saúde como sujeitos e objetos de experiências educativas. Saúde e Sociedade, São Paulo, v. 3, n. 2, p. 127-148, 1994. 